\title{
Understanding spatial variations in the impact of accessibility on land value using geographically weighted regression
}

\section{Hongbo Du}

Dongguan Institute of Urban Planning and Construction ${ }^{\text {a }}$

\author{
Corinne Mulley
}

University of Sydney ${ }^{b}$

\begin{abstract}
This paper aims to understand the spatial variability in house prices and accessibility. The motivation for understanding the connection between accessibility and house prices stems from the increasing attention given in recent years to the potential for funding transport infrastructure by land value capture policies. Establishing whether there is identifiable land value uplift, and further quantifying this uplift, is a prerequisite to sensible discussions on the potential for land value capture. Although there has been substantial related research in the United States, not only have there been fewer studies in the United Kingdom, but these have concentrated on London. London, as a capital city, differs in many respects from other cities. Large conurbations such as Manchester, Sheffield, and Tyne and Wear are more typical of British cities. This study focuses on the Tyne and Wear area, which has an extensive public transport system, with a light rail system-the Tyne and Wear Metro-forming the backbone of the public transport system. The investigation reported in this paper is underpinned by the use of Geographically Weighted Regression (GWR) methodology with property prices as the dependent variable, which in turn is explained by independent variables designed to standardize for household features and spatially defined factors including the transport accessibility of the house location. This methodology allows for estimation of the importance of transport accessibility in determining house prices.

The empirical results show that, on average, the internal factors of the property and the socio-economic classification of its location are dominant determinants of property prices, but transport accessibility variables are also significant. However, the local model approach of GWR shows a significant spatially varying relationship between property prices and transport accessibility to be identified.

This study contributes to a quantification of the impact of accessibility on house prices. Moreover, the paper demonstrates the application of a relatively new methodology in the transport field that takes account of the spatial nature of the data required in this process.
\end{abstract}

Keywords: accessibility, public transport, land value, land value capture

\section{Introduction}

Public transport investments improve accessibility for locations where users are served directly by this investment or use this investment as part of the public transport network. In general, improvements in accessibility are translated into enhanced land values; this process is called land value uplift. In recent years, land value uplift has attracted increasing attention as a potential means of financing transport infrastructure, particularly in the United Kingdom, where a swathe of new light rail schemes failed to be implemented because of a lack of funds (GVA Grimley 2004, 1). However, the empirical evidence to date is not sufficiently robust to identify how much transport infrastructure and its associated accessibility impacts contribute to land value uplift, and this is a prerequisite to sensible discussions on land value capture. In the early stages of seeking evidence on this matter, comparison methods were used (Pickett and Perrett 1984; Cervero and Landis 1993; Du and
Mulley 2006). Hedonic price methods have also been widely considered as an approach to identify the impact of transport investment on land value, and this is particularly so in the United States, (Weinberger 2001, Cervero and Duncan 2002a, 2002b). In the United Kingdom, two studies have employed a hedonic price approach to evaluate the impact of a light rail system on house prices in Manchester (Forrest and Glen 1995), and in Sheffield (Henneberry 1998).

However, to properly understand the relationship between transport infrastructure and land value, it is necessary to deal with spatial data. Hedonic models, as a subset of traditional multiple regression models, assume that the observations in the regression are independent of one another. This assumption is likely to be broken when data are spatially correlated (correlation of a variable with itself through space), as is common with geographical data. Geographical data are likely to follow the first law of geography, for which "everything is related to everything else, but near things are more related than distant things"

a duhongbo@gmail.com

b corinne.mulley@sydney.edu.au

Copyright 2012 Hongbo Du and Corinne Mulley.

Licensed under the Creative Commons Attribution - NonCommercial License 3.0. 
(Tobler 1970,236). This study uses a relatively new technique, Geographically Weighted Regression (GWR) (Fotheringham et al. 2002), to take account of spatial autocorrelation by adding a coordinate to each point to allow the effect of accessibility to be examined by use of a local model, with residential property prices as the dependent variable, which is then explained by a number of spatially defined factors including the transport accessibility of the house location. The quantification of transport accessibility in this way helps to identify value uplift and the potential for land value capture associated with transport investment.

This study contributes not only by the way in which the impact of transport accessibility on residential house prices is quantified for a conurbation outside the capital city, but also through a demonstration of a methodology that can handle the spatial nature of the data required in this process.

The paper is organized as follows: The next section outlines the existing literature relating to the impact of public transport infrastructure on residential land value and the methodologies of these studies in identifying value uplift. This leads to the methodology section, in which the use of GWR is justified and explained. A significant issue in the use of the GWR modeling technique is its requirement for data at a disaggregate level, and data acquisition issues are discussed in the following section. The analysis section presents and interprets the results, which is followed by a concluding section.

\section{Background}

To look at the impact of transport infrastructure, it would be ideal to look at changes in unimproved land (i.e,, land with no structures on it), but this is impractical when looking at the impact on residential properties. Thus, studies on the impact of transport infrastructure on land value have concentrated on examining changes to property prices, controlling for the particular characteristics of the property. The underlying philosophy is that if all the features of the property can be taken into account, then the price of a property reflects the value of the land on which the property sits.

The literature presented in the next subsection reviews those studies looking at the impact of transport infrastructure on land value together with the methods used to value these impacts. The following subsection reviews the possible methodologies for measuring impacts to explain the choice of Geographically Weighted Regression (GWR) in this study.

\subsection{Impact of public transport infrastructure on resi- dential land value}

RICS (2002), Debrezion et al. (2007), and Smith and Gihring $(2006,2009)$ together provide major reviews of more than 100 international studies on the impact of public transport on property values. These reviews identify that the literature on the impacts of public transport has focused almost exclusively on the impact of rail projects: heavy rail, metro, and light rail.

The literature on rail-based infrastructure impacts demonstrates highly variable premiums, partly due to different methodological and data constraints of the studies. In the United States, evidence of the impact of transport infrastructure on land value has shown mixed findings. Both negative and positive results have been attributed to rail transit provision, with some studies giving statistically significant evidence of residential property price increases of up to 25 percent (Cervero and Landis 1993; Armstrong 1994; Landis et al. 1994; Cervero 1998; Cervero and Duncan 2001, 2002a, 2002b; and Hack 2002). A study of Toronto, Canada, found positive land value uplift for subways but negative value uplift for highways (Haider and Miller 2000).

In the United Kingdom, a south London property developer estimated that the London Jubilee Line extension has increased the land value around underground stations by an amount that, in total, is nearly four-fold the line's building cost (Riley 2001); a different study found positive but uneven results in residential property price change along the same line (Chesterton 2002). No significant effect was found for house price change in the proximity of the Croydon Tramlink, but this study suggests these results were related to timing issues (RICS 2004). The first study on the impacts of Tyne and Wear Metro revealed that residential house prices rose around two of the metro lines but fell near the other two metro lines (TRRL 1984). A more recent study into the longer-term impacts of the Tyne and Wear Metro failed to identify statistically significant results of land value uplift that could be attributed to the metro (TRRL 1993). Similar findings were highlighted in the Manchester Metrolink study (Forrest and Glen 1995), with a very small discrete transport-induced price rise identified by an evaluation of the Sheffield Supertram (Henneberry 1998).

The contribution of new bus-based infrastructure to land value uplift is an area that has only recently emerged in the literature, despite the progressive implementation of bus rapid transit (BRT). As notable exceptions, both Rodriguez and Targa (2004) and Munoz-Raskin (2009) studied the impact of BRT in the context of a large city in a developing country, focusing on the Transmilenio in Bogota, Colombia. They found 
that, as for rail, the housing market placed value premiums on residential properties in the immediate walking proximity of feeder lines to the BRT service. Cervero and Duncan (2002) found no evidence of appreciable effects of BRT on multifamily housing in Los Angeles, although this study was conducted only one year after the BRT opened, and for this system there was no dedicated right-of-way as well as stops being in redevelopment districts. In contrast, McMillen and McDonald (2004) found that the housing market in Chicago capitalized the impact of a new rapid transit line six years before its opening. More recently, Des Rosiers et al. (2010) investigated the impact of bus services on residential property values in Quebec, Canada, using a hedonic pricing model and found differing uplifts for houses close to regular routes (negative uplift) as opposed to express routes (positive uplift), but that greater opportunities in terms of an increase in destination choice added positively to house prices.

The variation in effects exposed by the literature, in terms of the amount of uplift, timing of impacts, relevance of mode, and potential causal links, indicates the importance of not overstating the accessibility impacts of new infrastructure. Hall and Hass-Klau (1985) argue that transport changes facilitate urban change but do not bring about the change by themselves. This was reinforced by Knight (1980), who suggested that for substantial land use impact to occur, it needed the synergies of coordinated land use policies, developable land, and favorable regional development trends and social and physical conditions. The success of London Dockland's development, following the introduction of Dockland Light Railway, is a good example of this.

\subsection{Methods to evaluate impacts}

Methods that have been used to evaluate impacts include simple comparison and hedonic price models. Methods based on simple comparisons have been employed in a number of studies (TRRL 1984; Cervero and Landis 1993; TRRL 1993; Pasha 1995; Du and Mulley 2007). The price changes of houses in the catchment areas of a station are compared with the property price changes in control areas, but this method seems unable to identify the more complicated, multi-dimensional features that underpin property values.

While the comparison method examines the relationship between land value or property price and transport accessibility by isolating transport accessibility from other factors through comparisons of land value/property price, the hedonic pricing method examines this relationship by standardizing for a number of attributes in a multiple regression model with the dependent variable of land value/property price. Hedon- ic models have been the most common approach to analyze property prices, using a multiple regression methodology to explain house prices as a function of a number of house-specific explanatory variables as well as a methodology to identify the effects on house prices of factors such as proximity to transportation facilities (Cervero and Duncan 2001).

However, literature (Landis et al. 1994; Cervero and Duncan 2002a, 2002b) points to the variability of transport accessibility and land value over space: in hedonic modeling this has been met by applying hedonic price models to either submarkets or to different types of properties as in Adair et al. (2000). These approaches require the land area to be subdivided using some arbitrary "rule" to give boundaries for the separate hedonic models.

The interpretation of hedonic-based analyses can be problematic; issues over which variables should be included in the model specification and in interpretation, particularly the best way to choose between competing models on the basis of model fit when models may include different variables and have different functional forms. An additional issue for hedonic price models is the need to use a functional form that satisfies the assumptions of multiple regression (Forrest and Glen 1995; Weinberger 2001), which may not give rise to easy interpretation. Perhaps more importantly, hedonic models in the presence of spatial autocorrelation and/or spatial heterogeneity (or spatial non-stationarity) will have parts of their unexplained variance caused by interdependence between observations as a result of their relative location in space. Unless the models can be adjusted for these effects, then - using the terminology of Anselin (1999) — spatial dependence (where the dependent variable is associated with a lagged effect) gives rise to biased estimated coefficients, and spatial error dependence (where the error term follows a spatial autoregressive process) means that although the estimated coefficients remain unbiased they are inefficient (Rodriguez and Targa 2004). Spatial non-stationarity is more difficult to address without the use of spatial models.

Spatial models that recognize directly this variability have become more accessible in recent times through improvements in computing power and available software, which in turn has given rise to an increase in the use of local models. This study is a demonstration of recognizing the spatial variability of land values directly in its use of Geographically Weighted Regression (GWR), which estimates a hedonic model as the global model and is then extended to produce a local model at each point of the data. The methodology of this modeling technique is discussed next, together with alternative spatial modeling approaches, to justify the use in this study of the GWR approach. 
3

\section{Methodology}

As identified above, many studies have used a hedonic modeling approach (essentially a traditional multiple regression model formulation) to examine the effect of transport infrastructure on land value. The hedonic modeling approach effectively standardizes for the internal qualities of the property so that the effect of accessibility on house price can be derived. In contrast, this study uses a local model approach in which first a global model is calibrated that is equivalent to a hedonic model, then a second stage develops the more disaggregate local model estimates. This section looks in more detail at the reasons for the use of the GWR approach and outlines the methodology of GWR.

In traditional multiple regression, it is assumed that the relationship to be modeled holds everywhere in the study area. However, this is often violated in the analysis of house prices due to the presence of spatial effects that can be seen by mapping the residuals of the multiple regressions when distinct spatial patterns can be identified. Spatial effects may occur in two different forms as discussed above: one is concerned with spatial dependency, or its weaker expression, spatial autocorrelation (they are not identical, though they are often used interchangeably in the literature). The other form is spatial heterogeneity-namely, spatial non-stationarity (Anselin 1999). Spatial autocorrelation can be seen as spatial interaction while spatial heterogeneity (spatial non-stationarity) refers to spatial structure (Anselin 1999). Spatial dependency and spatial non-stationarity have been the major challenges in spatial data analysis (Fotheringham et al. 2002). Indeed, as a local spatial modeling technique, GWR not only tackles spatial non-stationarity by accounting for coordinates in parameter estimates but also deals with spatial dependency by taking into account geographical location in intercepts. With the allowance of spatial non-stationarity in the regression parameters, GWR local models can improve global models by accounting for some or even a large part of spatial autocorrelation in error terms. Although not widely used in transport studies, GWR has been identified as providing more rigorous analysis of change over other spatial analytical tools if its significant data demands can be met.

Moving away from hedonic price models to models that more directly account for spatial relationships between variables opens up a number of possibilities, each with its associated merits in comparison to the GWR methodology. In contrast to the GWR approach, spatial lag models extend the autoregressive models typically used in time series modeling. In these, spatial relationships are taken into account by the use of a lagged dependent variable.Its computation is more difficult but can be undertaken with maximum likelihood or instrumental variables estimation. However, the estimation gives results which, unlike GWR, cannot be easily related to geographical space. Spatial error models are another alternative that, in contrast to a spatial lag approach, assume it is the error term itself that can be defined to capture spatial correlations in the model. Spatial lag models are typically estimated using maximum likelihood techniques but, as with spatial lag models, the estimates from these models are not easily related to geographical space. As this study is focusing on indentifying variability and not just taking spatial relationships into account in the modeling process, GWR is identified as a superior methodology.

The modeling approach of this paper is discussed in the next section, starting with the global model and moving then to the local model, with the following section describing how the significant data collection requirements of GWR are met.

\subsection{Global regression model}

"Location, location, location" is the mantra of the real estate industry, suggesting that house prices are determined not only by internal factors, such as the quality of the house itself, but also by external factors, which are highly related to location (such as accessibility and environment). This study has defined a global model for which house prices are effectively standardized for internal factors and environmental factors so that the relevance of accessibility and location can be determined. This is equivalent to studies using a hedonic modeling approach.

The model used thus relates the dependent variable of house price to a group of variables, as follows:

$$
P_{i}=f(C, T, N)
$$

where $\mathrm{C}$ is a vector of characteristics of properties (whether it is flat, terraced, semi-detached, or detached) and the number of bedrooms; $T$ is a vector of transport accessibility, measured as travel time to employment opportunities using an accessibility measure by public transport (based on timetables) and travel time to the city center (Haymarket) by car (using an algorithm of minimum path build)_assuming that the network of roads was halfway between the congested peak hour and free flow levels; and $\mathrm{N}$ is a vector of the neighborhood environment effects captured by income (measured by the percentage of higher professional occupations and the percentage of long term unemployment), ethnic characteristics of the area (measured by the percentage of ethnic minority), and accessibility to schools (which has been identified as one of the key factors for determining the location of houses in Tyne and Wear) (TRRL 1984). The accessibility to schools was con- 
trolled by the average point score of the nearest primary school, which was calculated by allocating points to each pupil's exam results in nationally based statutory tests and dividing this total by the number of eligible pupils in each subject (DfES 2004). Accessibility data for public transport and car journeys were provided by local government partners from modeling undertaken to fulfill their statutory commitments to provide a Local Transport Plan. The accessibility data were an output from the Tyne and Wear Transport Accessibility Model (which was being developed at the time of this study), and its methodology, following the requirements of the UK central government, was outside the control of the study reported in this paper.

The data requirements of the modeling are constrained by the need to provide disaggregate data for the local model. Thus, census data are collected at the census output area level- the smallest unit of census geography-and covered between 100 to 125 households in the UK 2001 Census.

The global model estimated was:

Ln $\mathrm{P}_{\mathrm{i}}=\alpha_{0}+\alpha_{1}$ BEDROOM $_{i}+\alpha_{2}$ FLATBED $_{i}+\alpha_{3}$ SEMIBED $_{i}+$ $\alpha_{4}$ DETABED $_{i}+\alpha_{5} \mathrm{SP}_{-} \mathrm{AVE}_{i}+\alpha_{6} \% \mathrm{ETHNM}_{i}+\alpha_{7} \% \mathrm{HPROF}_{i}$ $+\alpha_{8} \% \mathrm{UNEM}_{i}+\alpha_{9} \mathrm{CAR} \_A C C_{i}+\alpha_{10} \mathrm{PT}_{-} \mathrm{ACC}_{i}$

\section{where}

Ln $\mathrm{P}_{i}$ is the natural logarithm of $\mathrm{P}_{i}, \mathrm{P}_{i}$ is the asking price in pounds sterling, and BEDROOM is the number of bedrooms in the property. FLAT, TERR, SEMI, and DETA formed a set of dummy variables that depict the type of property and are incorporated in the model as an interaction term with BEDROOM (to create the variables FLATBED, TERRBED, SEMIBED, and DETABED) to capture the conditional effects of the number of bedrooms and type of property; $\mathrm{SP}_{-}$ AVE is the average point score of the primary school in 2003 nearest to the house, derived from the performance statistics (DFES 2004); \%UNEM is the percentage of long-term unemployment in the census 2001 output area in which the house is located; \%HPROF is the percentage of higher professionals, including large employers and highest managerial occupations and higher professional occupations, in the census 2001 output area in which the house is located; \%ETHNM is the percentage of ethnic minority in the census 2001 output area in which the house is located; CAR_ACC is the car travel time (minutes) to the city center at a half-congested network level; and PT_ACC is the public transport travel time (minutes) to employment by public transport (including both Metro and bus). The descriptive data for these explanatory variables are shown in Table 1.
Table 1: Variables and their descriptive statistics $(\mathrm{n}=1690)$.

\begin{tabular}{cccc}
\hline & Units & Mean & Std. Deviation \\
\hline P (Price) & $£$ & 162812.15 & 80463.087 \\
$\operatorname{lnP}$ & $£$ & 11.89 & 0.4891 \\
BEDS & integer & 2.83 & 0.961 \\
SP_AVE & Point score & 27.16 & 1.9356 \\
ETHNM & $\%$ & 3.43 & 5.13616 \\
HPROF & $\%$ & 8.63 & 7.01979 \\
UNEM & $\%$ & 1.32 & 1.33783 \\
CAR_ACC & minutes & 16.33 & 4.69079 \\
PT_ACC & minutes & 27.38 & 6.18073 \\
\hline
\end{tabular}

\subsection{The local model of Geographically Weighted Regression (GWR)}

Geographically Weighted Regression (GWR) as a technique was developed by Fotheringham et al. (2002). It extends the traditional cross-sectional regression model, which can be written as

$$
Y_{i}=\beta_{0}+\Sigma_{k} \beta_{k} \beta_{i k}+\varepsilon_{i}
$$

to a model in which local variations in the parameter values can be estimated by taking into account the coordinates of the variable. If the dependent variable has coordinates $\left(\mathrm{u}_{\mathrm{i}}, \mathrm{v}_{\mathrm{i}}\right)$, the model expressed in (3) above can be rewritten as:

$$
Y_{i}\left(u_{i} v_{i}\right)=\beta_{0}\left(u_{i} v_{i}\right)+\Sigma_{k} \beta_{k}\left(u_{i} v_{i}\right) \beta_{i k}+\varepsilon_{i}
$$

This can then be fitted using a weighted least squares method to give an estimate of the parameters at the location $\left(u_{i}, v_{i}\right)$ and a predicted value of $y$, where the weights are chosen so that observations near the point in space where the parameter estimates are chosen $\left(\mathrm{u}_{\mathrm{i}}, \mathrm{v}_{\mathrm{i}}\right)$ have more influence on the result than observations further away. By this geographically weighted calibration, estimates of the parameters can be made for each data point with coordinates, which then can be mapped. This unique advantage of GWR over some other spatial methods is that each observation is treated as an individual observation at a specific geographic point as opposed to an observation lying within an artificially bounded geographical area (for example, within a particular political boundary), as required by other methodologies used in spatial analysis such as multi-level modeling.

Estimation is a trade-off between efficiency and bias in the estimators. The weighting process is undertaken by the use of spatial kernels, which capture the data points to be regressed 
by moving the regression point across the region. The weight is measured through the bandwidth against the distance from data point $j$ to regression point $i$. Regression results are very sensitive to the choice of bandwidth, and the GWR software allows the choice of adaptive spatial kernels to be used so that the bandwidth is narrow when data are dense but allowed to spread where data are sparse. The Akaike Information Criterion (AIC) (Akaike 1973) is used as the measure for evaluating the explanation given by GWR models as, in addition to measuring goodness of fit, it takes the complexity of the model into account. A rule of thumb is if the AIC of two models differs by more than three, then the models are statistically significantly different, with the lower AIC suggesting a better fit (Fotheringham et al 2002). If adaptive kernels are used in the estimation process, the GWR software chooses bandwidths so as to minimize AIC. This is explained in more detail in Fotheringham et al (2002).

In practical terms, collecting sufficient disaggregate data is the most critical aspect of applying this spatial technique. Data acquisition issues are discussed in the next section.

\section{Data Acquisition}

The Tyne and Wear Metro is the focus of the case study. Tyne and Wear is a conurbation in the northeast of England. In public transport terms, the area is served by a light rail system, Metro, which opened in 1980 on the route of a heavy rail system with some new tunnel links.

Only part of the area is covered by Metro (Figure 1); the rest of the area is served by bus. Metro was extended in 2002 to Sunderland in the southeast, but this area is not included in this study. For private transport, the area benefits from good arterial road access as shown in Figure 1. Car ownership is low for the United Kingdom, with a low average number of cars per household compared to England as a whole (TWWP (2005)), and congestion on these roads is low as well, even at peak times.

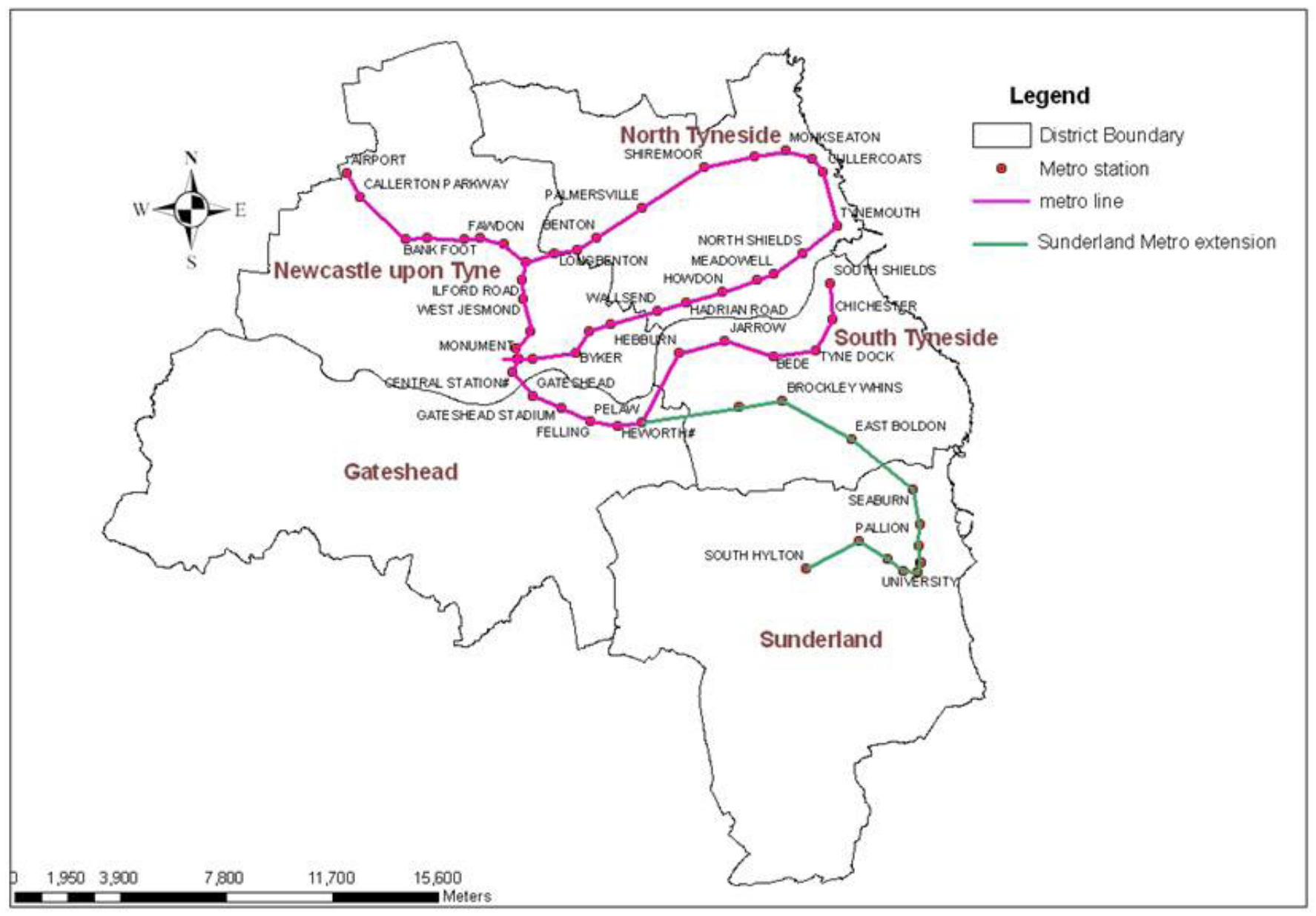

Figure 1: Map of Tyne and Wear Metro.

Source: Based on Tyne and Wear Accessibility Modeling and Edina Digimap. 
This study required property price data, socioeconomic data, and importantly, good quality transport accessibility data. Many data sources were explored before making the decision on which sources to use for the study.

\subsection{Property data}

Land value is examined in the form of house prices in this study. The house price is the value of the land together with the property built on it. This study uses residential property prices but standardizes for the features that have improved the land in order to identify the underlying land value.

Transaction property price data are normally considered the ideal data for property-related analysis on the grounds that these prices are the agreed upon and accepted prices by the market. Transaction data with sufficient information about the internal features of the property are unavailable in England because of confidentiality. As asking prices are available, these form the basis of this study. Asking prices can be considered expected prices based on the valuation of experts, and while these are expected to reflect a market valuation, there may be some unrealistic and extreme cases. Indeed, asking prices may be more appropriate than transaction prices for the purpose of examining the effect of external factors, such as transport accessibility, influencing house prices, since these factors may well be more generalized in terms of external and internal factors as compared to transaction prices, which are more likely to vary due to internal factors such as decoration style, garden, or parking space. There is, of course, a high correlation between asking and transaction prices, and for the period covered by this study the transaction house price achieved was, on average, 98.6 percent of the asking price in the North Region of the United Kingdom (Hometrack 2005).

Current property asking prices advertised on the Internet were drawn from a website www.icnewcastle.co.uk which provides a service called "icproperty" containing the advertisements of property for sale in Tyne and Wear. The advantages of this source is that it gives sufficient information about the property and the neighborhood environment at full six-digit postcode level (which has an average of 15 properties per postcode) to allow the study to add demographic and socialeconomic factors to each property from the census. These data were collected at the six-digit postcode level for one day in May 2005 and, in total, provided nearly 1700 properties for the districts of Newcastle City, Gateshead, and North Tyneside and South Tyneside within Tyne and Wear. The main advantages of using asking prices from the Internet has been the easy access to considerable data that include information on internal features, as well as that it gives a sample originating from a number of major estate agencies in Tyne and Wear area rather than relying on a single property agency. A separate investigation revealed about 95 percent of all properties from the relevant estate agencies were provided to the "icproperty" website, identifying that the majority of properties for sale are captured by this data collection process. A rather unique feature of the UK property market should also be noted at this stage: the internal space, in terms of square area, is rarely used as part of a market valuation, and indeed is not recorded even in transaction price data. In urban areas the conventional wisdom is that the availability of gardens, etc., do not add so much to the house price as to the speed in which a property sells. However, an obvious disadvantage of this data source was that a great deal of manual work was involved in the collection of data both in its downloading and formatting. In addition, the age of the property was unavailable, although information about the type (whether it is detached, semi-detached, terraced, or a flat) was available and, in the context of Tyne and Wear, provides a good proxy for age.

\subsection{Transport accessibility}

The literature described in the first section identifies the accessibility of a location, determined mainly by the transport system and land use pattern, as an important element of the external factors that influence house prices, making a discussion of the transport accessibility central to this study. The term "accessibility" has been debated in the transport planning literature for some time. In this study, accessibility is used to refer to the ease with which the land use and transportation systems enable individuals to reach activities or destinations (Morris et al. 1979; Handy and Niemeier 1997; Zhu and Liu 2004; Horner and Mefford 2005).

How to measure accessibility has been a significant issue, drawing a great deal of attention from both academic and practical viewpoints. Accessibility implies the ease of reaching somewhere, thus travel distance, time, or cost between origins and destinations can describe accessibility on the grounds that it measures the degree of ease. This is the simplest way to measure accessibility, and it is easy to understand. Accessibility is perhaps more rigorously measured by the potential opportunities at destinations involved in activities from a specific origin to a destination, because this allows multiple links of a transport network to be included. Using these ideas, accessibility measures can be subdivided into three main forms (DfT 2004). Infrastructure-based measures measure travel speeds by different modes, operating costs, and congestion levels. These are theoretically weak because they reflect only the level of throughput on the infrastructure and take no explicit account of the land use component. Gravity-based measures are an im- 
provement over these infrastructure-based measures because they attempt to reflect travel behavior realities through the functional form by making the potential attractiveness an inverse function of the distance between origin and destination. Utility-based measures reflect individual preferences and are based on an individual's actual choice set. Grounded in microeconomic theory, whereby an individual makes his or her travel choice by maximising his or her utility (Handy and Niemeier 1997), utility-based accessibility measures are normally derived using discrete choice modeling, which has a long tradition of application in the transport domain.

The specification of a measure for accessibility is critical. This is especially so when moving to the use of a lower level of data aggregation, as with GWR. Travel time to activities has been found to be a significant factor in house location choice for all types of household (Zondag and Pieters 2005). In terms of the relationship between transport accessibility and land use, the jobs-housing concept has long been the center of transport and land use studies (Ma and Banister 2005). As a result, employment is now considered the most likely single destination type for an accessibility measure on the grounds that commuting is probably the most regular form of travel (Horner and Mefford 2005). While utility-based measures are theoretically appealing because of their grounding in behavioral theory and welfare economics, they still have some theoretical shortcomings. For example the assumption of defining utility as linear with respect to income and the intrinsic travel bias does not explain non-travellers or the behavior of an individual who "trip chains."

Accessibility values were provided by the local government partner and calibrated to one-minute intervals for this study, which provided the level of disaggregation required. Car accessibility was calculated using the highway speed (between a fully congested network and a free-flow network) using an algorithm of minimum path build to give travel times for journeys to the city center of Newcastle as the place with the greatest concentration of employment. Public transport accessibility was calculated using a gravity=based Hansen method, using timetabled times, to all employment opportunities, weighted by the distance to the origin as reflecting the most frequent destination type. While these measures did take account of the location of stops and stations, no additional weight was given to houses located close to stations or stops, although the literature does identify that perceived or actual closeness to stations may increase house prices more (Adair et al 2000; Hess and Almeida 2007).

\subsection{Social economic data}

Social economic data, including data on income and ethnic group, were derived from the 2001 UK census at the level of Output Areas (OAs), which were created, as far as possible, by grouping together six-digit postcodes to give better integration between the geographical information referenced by census and postcode geographies. On average, OAs contain between 200 and 400 people (between 120 and 150 households), and there are approximately 3714 OAs in Tyne and Wear. As the property data were obtained at six-digit postcode level, each property was mapped at the centroid of the six-digit postcode unit, and then social economic data was allocated to each property by GIS.

\section{$5 \quad$ Analysis}

This research concentrates on the labor market provided by Newcastle city center and therefore, on the impacts of the original and major phase of the Tyne and Wear Metro. The results are shown below in two stages. The first part shows the results from the global regression analysis, showing parameter estimates and the associated t-statistics; this global result is the equivalent of a hedonic price model and gives average results for the area without any variability over space. The second part shows the local results, together with appropriate diagnostic information, mapped using GIS so that the spatial variation can be seen clearly; this is the added value provided by the use of GWR in this analysis.

\subsection{The results from global regression model}

The diagnostic information suggests that 38 percent of the variation in the dependent variable is explained by this global model (adjusted $\mathrm{R}_{2}$ ), which is a reasonable fit given the crosssection nature of the data. The dependent variable is the natural logarithm of house price, and Table 2 gives the independent variables, as described above in equation 2 , the parameter estimate and the significance (p-value). The dependent variable was transformed to natural logarithms to ensure the normal probability plot of the residuals followed a straight line. 
Table 2: Results of global regression parameters.

\begin{tabular}{|c|c|c|}
\hline PARAMETER & ESTIMATE & Significance (p-value) \\
\hline INTERCEPT & 11.965 & 0.000 \\
\hline BEDS & -0.074 & 0.000 \\
\hline FLATBED & 0.070 & 0.000 \\
\hline SEMIBED & 0.082 & 0.000 \\
\hline DETABED & 0.092 & 0.000 \\
\hline SP_AVE & -0.009 & 0.085 \\
\hline ETHNM & 0.001 & 0.685 \\
\hline HPROF & 0.029 & 0.000 \\
\hline UNEM & -0.074 & 0.000 \\
\hline CAR_ACC & 0.021 & 0.000 \\
\hline PT_ACC & -0.012 & 0.003 \\
\hline
\end{tabular}

As this is a semi-log functional form, the interpretation of the estimated coefficients relates to their proportional (or when multiplied by 100, the percentage) effect on Price. For the internal factors of the property, it can be seen that there is significant interaction between the size of the property, measured by the number of bedrooms, and the property type as well as a significant estimated coefficient for the number of bedrooms. The interpretation of these interaction terms is that, within a given property type, there is a differential impact of the number of bedrooms on the price of property and moreover, this differential impact declines when moving from detached houses to the higher density flat type. To understand the impact of an additional bedroom, the estimated parameter for BEDS needs to be taken into account and thus, the global regression suggests that, ceteris paribus, an additional bedroom in a detached house will lead to an 1.8 percent $(-0.074+0.092$ $=0.018)$ increase in price.

With respect to the socioeconomic factors, the percentage of ethnic minority residents and the percentage unemployed (ETHNM and UNEM, respectively) might be expected to vary with property value, but only the percentage unemployed was significant in the global regression, with an increase in 1 percent in unemployed, ceteris paribus, leading to a 7 percent decrease in property price. Having a higher percentage of professional residents (HPROF) and having a better school nearby would be expected to lift property value, and while this is the case for HPROF (adding nearly 3 percent to property price), the school variable (SP_AVE) is not significantly different from zero. However, the factors of high professional residents and levels of unemployment reflecting income of residents do, as expected, significantly contribute positively and negatively to property value respectively.
In terms of car and public transport accessibility, greater travel time implies worse accessibility and vice versa. If accessibility improves, then everything else being held constant would suggest that the estimated parameters should be negative, as one additional minute of car/public transport travel time (implying less good accessibility) is expected to lead to lower property prices. Both estimated parameters are significant, and the estimate for the public transport parameter PT_ACC is negative, albeit with a small absolute value of 1 percent. At the mean, a one-minute saving in public transport travel time equates to an approximately 3 percent saving from the average time (see Table 1) and generates a house price premium of approximately $£ 1600$ (1 percent of the mean price; see Table 1 ). For the car variable, CAR_ACC, the estimated parameter is significant but positive, suggesting that longer travel times to the city center have higher property prices. In general this applies to houses located further away from the city center and is evidence of the general trend of suburbanization in the United Kingdom, which is so noticeable in the Tyne and Wear area. It should be noted that, while this global regression used car accessibility times based on a road network between congested and free flow, the modeling was not sensitive to whether this accessibility or one based on the full or free-flow network was used.

The next section considers the effect of geography, as identified by the local GWR model.

\subsection{Local model: the GWR estimation}

One of the advantages of the GWR model is the ability to examine the spatial variability of independent variables included as explanatory variables. Some independent variables, therefore, might be non-significant in the global regression model but might vary significantly over the geographical area and be revealed as significant local parameters by the GWR modeling. It is expected that mapping the estimated parameters for public transport accessibility to employment, using the results of the local estimates from GWR, will show these distributed in accordance with public transport facilities such as bus stops and Metro stations, and the estimated parameters for car accessibility to the city center are expected to show a relationship with good road access, such as arterial roads.

The GWR software provides diagnostic information to assess whether the local model is an improvement over the global model described above. In this analysis, the local model benefits from a higher adjusted coefficient of determination (adjusted $\mathrm{R}_{2}$ ), from 0.328 to 0.467 , and a lower AIC (from 1721 down to 1392), suggesting that the GWR local model gives a significantly better explanation, after taking the degrees 
of freedom and complexity into account.

As identified above, one of the advantages of GWR is the ability to examine spatial variability that might otherwise be hidden in a global regression model. Property prices are very likely to vary over the geographical area. Based on a Monte Carlo significance test procedure, the GWR software can examine the significance of the spatial variability of parameters identified in the local parameter estimates. The results of these tests, shown in Table 3, demonstrate that there is highly significant (at the 5 percent level) variation in the local parameter estimates for all variables except the percent ethnic minority. The school point score varies significantly over space, although this variable was insignificant in the global regression, suggesting that this is a factor in some areas but not in others.

Table 3: The results of Monte Carlo significance test.

\begin{tabular}{ccc}
\hline PARAMETER & $\begin{array}{c}\text { SIGNIFICANCE } \\
\text { LEVEL FOR SPA- } \\
\text { TIAL VARIABILITY } \\
\text { (p-value) }\end{array}$ & $\begin{array}{c}\text { SIGNIFICANCE } \\
\text { LEVEL IN GLOBAL } \\
\text { REGRESSION } \\
\text { (p-value) }\end{array}$ \\
\hline INTERCEPT & 0.000 & 0.000 \\
BEDS & 0.000 & 0.000 \\
FLATBED & 0.000 & 0.000 \\
SEMIBED & 0.000 & 0.000 \\
DETABED & 0.000 & 0.000 \\
SP_AVE & 0.040 & 0.085 \\
ETHNM & 0.100 & 0.685 \\
HPROF & 0.000 & 0.000 \\
UNEM & 0.017 & 0.000 \\
CAR_ACC & 0.000 & 0.000 \\
PT_ACC & 0.000 & 0.003 \\
\hline
\end{tabular}

The results for the two variables — car accessibility (CAR_ ACC) together with the variable looking at public transport accessibility (PT_ACC) —are mapped next to examine their spatial variation because of this paper's focus on the impact of accessibility on house prices.

In Figures 2 and 3, the background shading refers to the significance of the local parameter estimates, which are shown as different colored points. Areas shaded grey contain local parameters that are statistically significant, with dark grey areas referring to $t$-values of less than -2 and light grey areas referring to $t$-values greater than +2 . The values of the local parameters have been colored so that positive values are shades of red while negative values are shades of green. It is clear from the maps that the parameters demonstrate considerable spatial variation.
Figure 2 shows that there is clear variation in the local parameter estimates for the variable PT_ACC over different areas. Everything else being equal, it is expected that quicker access by public transport (thus a decrease in time of access) will lead to an increase in house price, suggesting there should be a negative relationship between public transport travel time and property price. In Figure 2, there is a large area of significant and negative local parameters that covers the majority of the Newcastle upon Tyne District, overlaps into the Gateshead District in the south, and includes the central and most westerly parts of the Metro system. Using known information about Tyne and Wear, within this area, the effect is stronger in the poorer areas where savings in public transport accessibility of one minute give a bigger percentage change to house prices (up to 6 percent, as compared to the global average of 1.2 percent, shown in Table 2). This reflects the way in which public transport accessibility is likely to be more important to households with lower incomes, especially as car ownership is relatively low in Tyne and Wear. Figure 2 shows also that within this area there is a strong cluster of significant negative local parameters around the Metro link going north and west. These areas are regarded as wealthier and include inner suburbs that have been gentrified. Although a less strong effect, Figure 2 shows that the house price premiums associated with these locations are equal or greater (between 1 and 2 percent) to that identified by the global regression.

Similarly, Figure 3 exhibits clear variation in the local parameter estimates for the variable CAR_ACC over the different areas, being positive in most areas and negative in some. The geographic central core shows significant negative local parameters, although the absolute values are close to zero, suggesting that accessibility by car does not add a premium to house prices here. However, the locations of these properties are such that need to travel by car to the center is low, if nonexistent. This core is surrounded by an area of insignificant local parameters. On the outer area is a large area of significant positive local parameters. Positive parameters suggest that an extra minute of car travel time adds to house prices. These areas with positive relationships between car travel time to city center and property price are hypothesized to have other, stronger neighborhood features with specific amenities, such as the seaside (in the east), countryside (in the north and west), or proximity to a major shopping center (in the north part of Gateshead District). In the east in particular, it can be seen that there is a concentration of positive local parameters, suggesting one additional minute travel time by car increases house prices by more than 7 percent, as compared to the average of 2 percent identified by the global regression. The results suggest that 


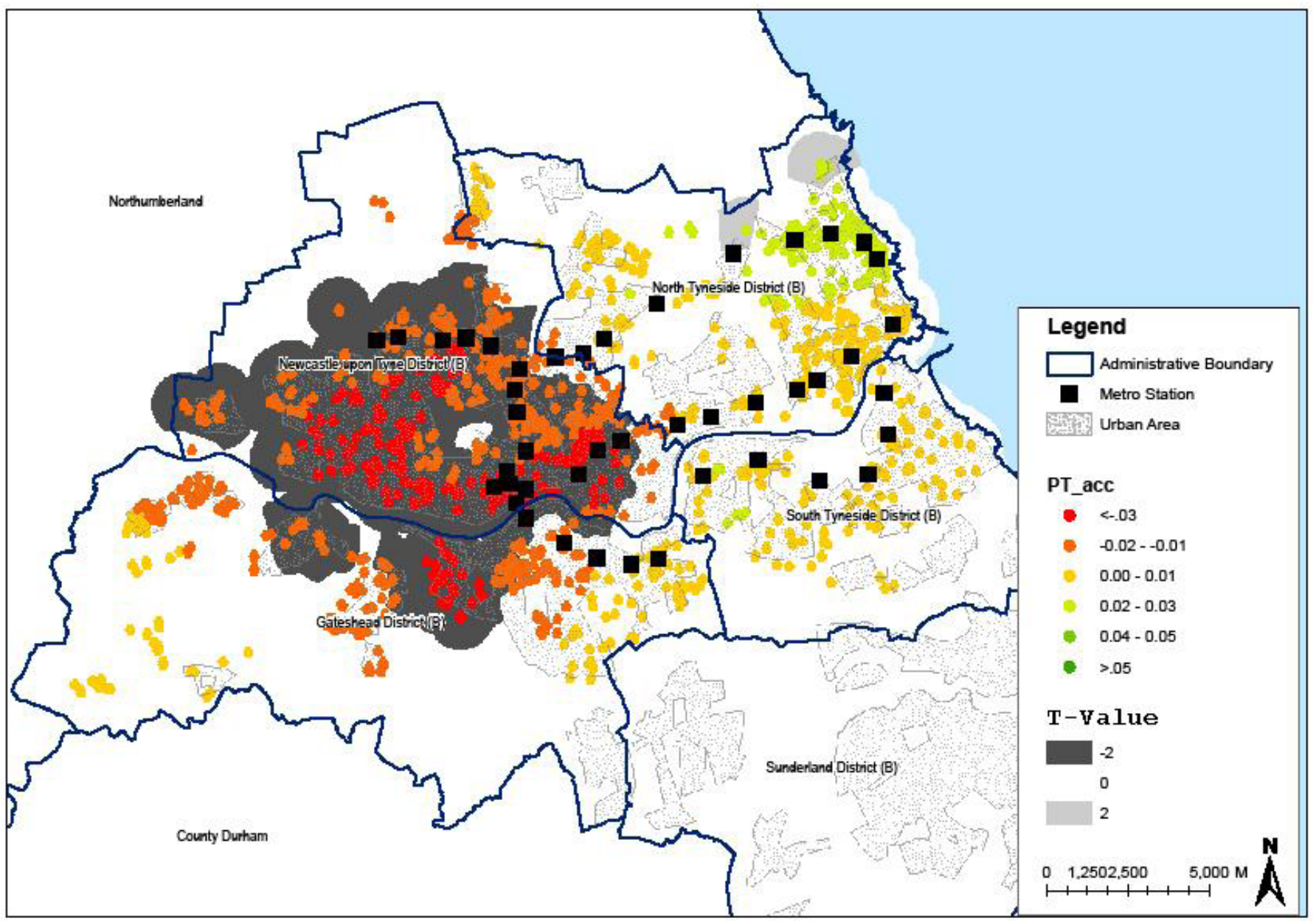

Figure 2: Map of the local parameter estimates associated with public transport accessibility (variable PT_ACC).

occupants of properties in these locations are prepared, ceteris paribus, to pay for suburban living with additional minutes travelling by car.

The way in which house prices vary over geographical space could be mapped for each of the independent variables identified in the model, as reported in Table 3, giving a set of maps which together would provide a fuller picture of the drivers of house price over geographical space. Indeed, while more difficult to present in two-dimensional space, the building of a multilayered map may be an alternative to simply considering a number of maps side by side.

As a way of modeling data with a spatial content, GWR provides an elegant way of estimation with outcomes that can be interpreted over geographical space. However, the literature identifies a significant theoretical issue arising from the additional complexities of the GWR estimation, potentially giving rise to multicollinearity or interrelationships among the local estimates even when there are no such relationships at the global model level. Checks for linear dependency at the global level were carried out by an examination of the correla- tion matrix and with regard to the stability of the parameter estimates and the associated standard errors. At the local level, checks for multicollinearity followed Wheeler and Teifelsdorf (2005), who propose a number of different tests for identifying the presence of multicollinearity; this work has followed two of these tests, which follow directly from GWR output (scatter plots between the local parameter estimates, supplemented by histograms of local parameter correlations) with little evidence of multicollinearity in this dataset.

As in all analysis, missing variables will lead to model specification problems. In this analysis, improvements in the model specification need to be considered in the context of the results discussed above. One category of missing variables is those variables which might better distinguish a property's internal factors - for example, the number of bathrooms or the existence of a garage. As these were unavailable, their absence is likely to have resulted in a depressed $\mathrm{R}_{2}$. A second category of missing variables, such as proximity to amenities, proximity to stations, parking availability, crime, and other social factors, also creates limitations in terms of model specification. But be- 


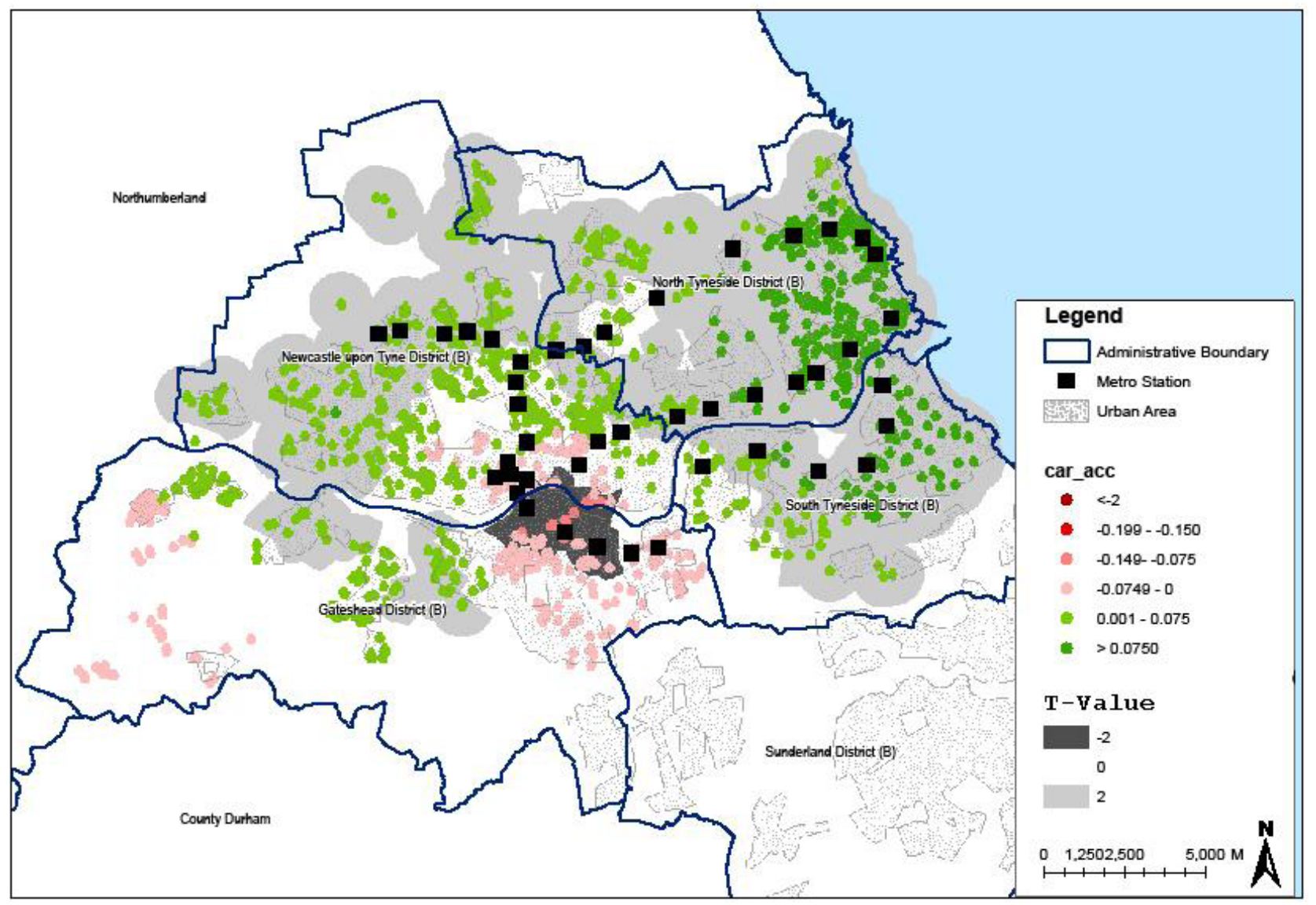

Figure 3: Map of the local parameter estimates associated with the car accessibility (variable CAR_ACC).

ing able to better standardize the internal features of a property that might allow variations in transport accessibility to become more visible is only partly a data availability issue, as it is also an issue of model calibration. Although adding variables to the model tends to improve the adjusted $\mathrm{R}_{2}$ there is always a risk of over-fitting the regression model, which would add noise to the calibration and actually reduce the reliability of the model.

\section{Conclusion}

In conclusion, a global regression model-as a hedonic model-offers the basis for explaining variation in property prices on an average basis, but gives no indication of spatial variability. Based on the results from the global regression model, property prices are mainly determined by the internal property factors and socioeconomic classification of the property location. But the additional information from the results from the local model using GWR clearly reveal a spatially varying relationship between property prices and the variables included in the model. The maps of this paper show that public transport accessibility does affect property prices, particularly in relatively poor neighborhoods. This suggests that providing light rail infrastructure as part of a network can have a positive distributional effect. In general, properties further away from the city center tend to be larger and in lower-density areas, as well as more expensive as a result of the suburbanization in Tyne and Wear (as in the rest of the United Kingdom) in recent decades. Equally interesting is the effect of gentrification, where the local GWR model shows that property value is increased by proximity to the city center.

The analysis was motivated by a desire to provide empirical evidence for uplift in land value following the provision of new transport infrastructure, which offered benefits in terms of enhanced accessibility. Evidence of this nature is a prerequisite to underpinning any new policy of land value capture. The evidence from this study shows, at the very least, that accessibility varies over space, having a positive effect on land value in some areas, but in others a negative or zero effect. Although neighborhood features may help to explain such variation, the implementation of a uniform land value capture policy would necessarily give rise to winners and losers and needs to be very carefully considered if it is not to turn out to be regressive. However, a better understanding of winners and losers may al- 
low such a land value capture policy to be introduced as a more progressive tax if "winners" are in the relatively poor areas and the "losers" are in areas where other external factors, such as the seaside, have a stronger effect. Indeed the results demonstrate a clear need to undertake analysis at a more disaggregate level and in a way that allows variation over space to be apparent.

\section{$7 \quad$ Acknowledgements}

The authors would like to acknowledge the support from Trevor Arkless at Newcastle City Council on behalf of Tyne and Wear Plan Partnership for his assistance with the acquisition of transport accessibility data. They also acknowledge the funding support from Newcastle University, School of Civil Engineering and Geosciences of Newcastle University, Rees Jeffreys Road Fund, RICS Education Trust, and The Henry Lester Trust Ltd.

\section{References}

Adair, A., S. McGreal, A. Smyth, J. Cooper, and T. Ryley. 2000. House prices and accessibility: The testing of relationships within the Belfast urban area. Housing Studies, 15: 699-716.

Akaike, H. 1973. Information theory and an extension of the maximum likelihood principal. Geographically Weighted Regression: The Analysis of Spatially Varying Relationships. Edited by M. Charlton. West Sussex: John Wiley and Sons.

Anselin, L. 1999. Spatial Econometrics. School of Social Sciences, University of Texas, Dallas.

Armstrong, R. 1994. Impacts of commuter rail service as reflected in single-family residential property values. Journal of Transportation Research Record, 15: 88-98.

Cervero, R. 1998. The Transit Metropolis: A Global Inquiry. Washington, DC: Island Press.

Cervero, R. and M. Duncan. 2001. Transit's value-added: effects of light and commuter rail services on commercial land values. Proceedings of the 81st Annual Meeting of the Transportation Research Board. Transportation Research Board, Washington, DC.

Cervero, R. and M. Duncan. 2002. Land Value Impacts of Rail Transit Services in Los Angeles County. National Association of Realtors, Urban Land Institute.

Cervero, R. and M. Duncan. 2002. Land Value Impacts of Rail Transit Services in San Diego County. National Association of Realtors, Urban Land Institute.

Cervero, R. and J. Landis. 1993. Assessing the impacts of urban rail transit on local real estate markets using quasi- experimental comparisons. Transportation Research part A: Policy and Practice, 27: 13-22.

Chesterton. 2002. Second Property Market Activity Final Report. Jubilee line extension impact study unit, University of Westminster.

Debrezion G., E. Pels, and P. Rietveld. 2007. The impact of railway stations on residential and commercial property value: a meta-analysis. Journal of Real Estate Finance and Economics, 35: 161-180.

Des Rosiers, F., M.Theriault, M.Voisin, and J. Dube. 2010. Does an improved urban bus service affect house values? International Journal of Sustainable Transportation, 4 (6): 321-346.

DfE, S. 2004. Performance tables 2003: Key stage 2 test results. Department for Education and Skills.

DfT. 2004. Technical guidance on accessibility planning in local transport plans. Guidance on Accessibility Planning in Local Transport Plans. Department for Transport, United Kingdom.

Du, H. and C. Mulley. 2007. The short-term land value impacts of urban rail transit: Quantitative evidence from Sunderland, UK. Land Use Policy, 24(1): 223-233.

Forrest, D. and J. Glen. 1995. The impact of a light rail system on the structure of house prices. Journal of Transport Economics and Policy, 30: 15-29.

Fotheringham, A.S., C. Brunsdon, and M.E. Charlton. 2002. Geographically Weighted Regression: The Analysis of Spatially Varying Relationships. Chichester: Wiley.

GVA. Grimley. 2004. Developing a methodology to capture land value uplift around transport facilities. Report for the Scottish Executive. ISBN 0-7559-3866-6. URL http://www. scotland.gov.uk/Publications/2004/11/20385/48337 (accessed 21 August 2012)

Hack, J. 2002. Regeneration and Spatial Development: a Review of Research and Current Practice. Toronto: IBI Group.

Haider, M. and E.J. Miller. 2000. Effects of transportation infrastructure and locational elements on residential real estate values: Application of spatial autoregressive techniques. Transportation Research Record, No. 1722: 1-8.

Hall, P. and C. Hass-Klau. 1985. Can Rail Save the City?-The Impacts of Rail Rapid Transit and Pedestrianisation on British and German Cities. Gower Publishing Company Ltd.

Handy, S.L. and D.A. Niemeier. 1997. Measuring accessibility: An exploration of issues and alternatives. Environment and Planning A, 29: 1175-1194.

Hess, B.D. and T.M. Almeida. 2007. Impact of proximity to light rail rapid transit on station-area property values in Buffalo, New York. Urban Studies, 44: 1041-1067.

Hass-Klau, C., G. Crampton, and R. Benjari. 2004. Economic 
Impact of Light Rail: The Results of 15 Urban Areas in France, Germany, UK and North America. Environmental and Transport Planning, England.

Henneberry, J. 1998. Transport investment and house prices. Journal of Property Valuation and Investment, 16: 144-158.

Horner, M.W. and J.N. Mefford. 2005. GIS-based strategies for measuring worker accessibility to job opportunities: The case of bus transit. Proceedings of the 84th Annual Meeting of the Transportation Research Board, Washington, DC.

Hometrack. 2005. Annual house price survey (UK). URL www.hometrack.co.uk .

Knight, R.L. 1980. The impact of rail transit on land use: Evidence and a change of perspective. Transportation, 9: 3-16.

Laakso, S. 1992. Public transport investment and residential property values in Helsinki. Scandinavian Housing \& Planning Research, 9: 217-229.

Landis, J., S. Guhathakurta, and M. Zhang. 1994. Capitalization of Transit Investments into Single-Family Home Prices. The University of California Transportation Center.

Lawless, P. and G. Dabinett. 1995. Urban regeneration and transport investment-A research agenda. Environment and Planning A, 27: 1029-1048.

Leung, Y., C.L. Mei, and W.X. Zhang. 2000. Statistical tests for spatial nonstationarity based on the geographically weighted regression model. Environment and Planning A, 32: 9-32.

Ma, K-R. and D. Banister. 2006. Extended excess commuting: a measure of the jobs-housing imbalance in Seoul. Urban Studies, 43 (11): 2099-2113.

McMillen, D. and J. McDonald. 2004. Reaction of house prices to a new rapid transit line: Chicago. Real Estate Economics, 32 (3): 463-6.

Morris, J.M., P. Dumble, and M. Wigan.1979. Accessibility indicators for transport planning. Transportation Research Part A, 13 (2): 91-109.

Munoz-Raskin, R. 2009. Walking accessibility to bus rapid transit: Does it affect property values? The case of Bogota, Colombia. Transport Policy, 17 (2): 72-84.

Pasha, H.A. 1995. Comparative statics analysis of urban land values in the presence of government regulation. Urban Studies, 32: 1505-1516.

Pickett, M.W. and K. Perrett. 1984. The effect of the Tyne and wear metro on residential property values. SR 825 , TRRL 29.

RICS. 2002. Land value and public transport stage 1-Summary of findings. RICS Policy Unit, Royal Institute of Chartered Surveyors. www.rics.org.

RICS. 2004. Land value and public transport stage 2-Summary of findings. RICS Policy Unit, Royal Institute of Chartered
Surveyors. www.rics.org.

Riley, D. 2001. Taken for a Ride. The Center for Land Policy Studies, London.

Rodriguez, D. and F. Targa. 2004.Value of accessibility to Bogota’s Bus Rapid Transit System. Transport Reviews 24 (5): 586-610.

Smith, J. and T. Gihring, 2006. Financing transit systems through value capture: An annotated bibliography. American Journal of Economics and Sociology 65 (3): 751-786. Updated as Smith and Gihring with Litman. 2009.

Smith, J., T. Gihring, with T. Litman. 2009. Financing Transit Systems through Value Capture: An Annotated Bibliography. Victoria Transport Policy Institute. www.vtpi.org .

So, H.M, R. Tse, and S. Ganesan. 1997. Estimating the influence of transport on house prices: Evidence from Hong Kong. Journal of Property Valuation and Investment, 15: 40-47.

Thomas, M. and G. Copley. 2002. Croydon tramlink impact study-Summary report. DfT.

Tobler, W. 1970. A computer movie simulating urban growth in the Detroit region. Economic Geography, 46: 234-240.

TRRL.1984. The impact of metro and public transport integration in Tyne and Wear. Metro Monitoring and Development Study. SR 478, TRRL.

TRRL.1993.The longer term effects of the Tyne and wear Metro. CR 357, TRRL.

TWWP. 2005. Local transport plan-Tyne and Wear 20062011. Tyne and Wear Plan Partners.

Weinberger, R. 2001. Light rail proximity: Benefit or detriment?-The case of Santa Clara County, California. Proceedings of the 80th Annual Meeting of the Transportation Research Board, Washington, DC.

Wheeler, D. and M. Tiefelsdorf. 2005. Multicollinearity and correlation among local regression coefficients in geographically weighted regression. Journal of Geographic Systems, 7: 161-187

Zhu, X. and S. Liu. 2004. Analysis of the impact of the MRT system on accessibility in Singapore using an integrated GIS tool. Journal of Transport Geography, 12: 89-101.

Zondag, B. and M.Pieters. 2005. Influence of accessibility on residential location choice. 84th Annual Meeting of the Transportation Research Board, Washington, DC. 